Hospital's Spinal Units in Roxburgh, near Boston. He became Associate Professor at Harvard University, and there he is in the happy situation of combining the practical work on paraplegia, with research at the University-a very satisfactory combination. He is one of the two people in the U.S.A.- - the other is Ernest Bors at Long Beach-who have really done outstanding work on the subject of paraplegia and it is with the greatest of pleasure that I ask him to take the chair.

Dr. H. Talbot. Sir Ludwig, distinguished guests, colleagues, I am deeply aware of the honour which you do me by allowing me to act as Chairman at this session. I am delighted at this, my first visit to Israel, observing, as everyone necessarily must here, the vigour and the energy, the intelligence and the courage of its people.

I am particularly pleased that this meeting happens to coincide with a milestone date in the establishment of your new Medical School which, I am sure, will join the ranks of the great schools of the world and maintain the high, in fact the exalted reputation of Israeli science and medicine.

Without further ado, I will ask Mr. Norman Gibbon, of Great Britain, to open this session.

\title{
CHANGES IN THE UPPER URINARY TRACT FOLLOWING VARIOUS TYPES OF INITIAL TREATMENTS
}

\author{
Some Basic Considerations and a Follow-up Report \\ By N. O. K. Gibbon, J. Cosbie Ross, and J. R. Silver \\ Liverpool Regional Paraplegic Centre, England
}

DESPITE the obvious benefits conferred by treatment in special centres, the paraplegic cannot yet expect a normal life-span. Nyquist and Bors (I967) reported an annual death-rate among their I85I traumatic paraplegics of $\mathrm{I} \cdot 6$ per cent. as compared with 0.83 per cent. for the population of California and confirmed the general experience that renal failure is still the most frequent cause of death.

The pathology of the kidney post-mortem has been described in detail by Tribe (1963) who found renal failure to be the major cause of death in threequarters of 84 chronic paraplegics who died of causes related to their paralysis. The features of chronic pyelonephritis were predominant, and although this disease was often associated with amyloidosis and post-hypertensive changes, both the amyloid deposits and the hypertension were deemed to have been due in no small measure to the renal sepsis itself.

As the infection in these cases is usually introduced during the initial bladder drainage, it is appropriate that those working in this field should attempt to compare the results of different types of early bladder management. We propose in this paper to discuss some basic problems concerning pyelonephritis and to try to relate these to the paraplegic situation. We shall then consider how the development of pyelonephritis might be influenced by various types of early bladder management and finally present a report from our own Centre. 


\section{BASIC PROBLEMS IN PYELONEPHRITIS}

The common urinary pathogens can multiply in urine as fast as in artificial fluid cultures (O'Grady and Cattell, I966). In spite of this, bacteria introduced into the healthy urinary tract are rapidly eliminated both in the experimental animal and in the human. Although the vesical epithelium may have anti-bacterial properties (Cox and Hinman, I96I), the self-sterilisation is largely due to a 'washout' effect, the mechanics of which have been expounded in an admirable way by O'Grady and Cattell (I966). In the upper urinary tract, the effect depends upon the urine flow rate being high relative to the volume of the system, whereas in the bladder periodic complete emptying is the important factor. Before all the organisms can be eliminated, some may invade the bladder-wall resulting in acute cystitis. The consequent frequency of micturition is clearly beneficial in reducing the bacterial population within the bladder, and the high fluid intake usually prescribed is helpful in several ways. Firstly, it increases still further the frequency of bladder emptying, and secondly it reduces both the rate of multiplication and the maximum concentration of the organisms present (O'Grady and Cattell, I966). As a result of these various factors, resolution is usually rapid even without treatment. However, if inflammatory changes around the ureteric orifices should render them incompetent there may be an episode of acute pyelonephritis due to reflux (Ross et al., I960).

In the presence of more than about $30 \mathrm{ml}$. of residual urine little wash-out effect can be expected unless the bladder can be emptied very frequently (O'Grady and Cattell, 1966). Doubling the urinary flow rate has the same effect as halving the residual, but the presence of vesical diverticula will aggravate the situation. It appears that a drastic revision in our standards of bladder emptying is called for when infection is present.

If chronic cystitis does develop, infection may spread to the kidneys by reflux or by ureteritis. The latter condition interferes with normal ureteric motility (Talbot, I958), and increases the dilatation of the upper urinary tracts which results from retention of urine in the bladder. The reduced perfusion/volume ratio will permit continued multiplication of bacteria in the pelvi-calyceal systems. Finally, acute or chronic pyelonephritis may result in multiple obstructions to the renal tubules by scarring of the pyramids, and the kidney infection may then become self-perpetuating as well as inaccessible to surgical treatment.

It seems relevant to point out here that untreated lower urinary tract obstruction in the non-paraplegic often leads to renal failure from aseptic hydronephrosis and tubular atrophy. Moreover, when a case of prostatic obstruction does become infected during drainage or operation, this infection is eliminated within a few months provided that there is neither residual urine nor irreversible dilatation of the upper urinary tracts (Wells, I952).

In applying these considerations to the paraplegic, it should be said at the outset that the function of the upper urinary tracts is unaffected directly by denervation. As Doggart et al. (I966) and Price (I968) have shown, the kidneys continue to function normally in paraplegia for prolonged periods provided only that recurring infection be avoided.

In acute cord lesions there is retention of urine and this is often ( 42 per cent. of our cases; Damanski, I965) followed by incomplete bladder emptying which 
may lead to dilatation of the ureters and kidneys. Subsequent urological progress will depend upon whether infection has been introduced during the initial period of bladder drainage:

(I) If infection has not been introduced, then poor bladder emptying may result in a slowly progressive aseptic hydronephrosis and renal failure.

(2) If the urine is infected, then poor bladder emptying may give rise to ascending infection as well as dilatation of the upper urinary tracts, and this is a potentially lethal combination. This infection will be eliminated only if efficient micturition can be restored before irreversible changes have taken place in the ureters and kidneys. It is therefore vital that any operative intervention required for reduction of residual urine should be carried out before infection and back pressure changes have become established, contrary to what has often been the custom in the past. Furthermore, it seems clear that any attempt to relate the condition of the paraplegic's upper urinary tracts to the initial bladder management should take into account the incidence, timing, and effectiveness of operations undertaken to improve vesical emptying.

\section{INFLUENCE OF INITIAL BLADDER MANAGEMENT}

Vellacott and Webb-Johnson (I9I9) reported early return of reflex bladder contractions as well as a very low infection rate in Io uncatheterised cases, and a policy of non-intervention was no doubt preferable to the crude forms of drainage then in use. However, bladder drainage is certainly unavoidable in the female for the prevention of incontinence. There is also evidence that non-intervention may result in serious dilatation of the bladder and kidneys (Damanski, I963a), and that manual compression of the bladder may aggravate the situation by promoting reflux (Band, I963).

The introduction of bacteria into the urinary tract is not the only hazard to be faced in drainage. The infection resulting may produce secondary changes which lead to stasis of urine and so encourage proximal spread of the bacteria:

(i) Urethritis may give rise to stricture and contribute to bladder-neck obstruction.

(ii) Cystitis may result in impairment of vesical contractions and reflux as well as bladder-neck obstruction.

(iii) Ureteritis may interfere with peristalsis and even cause stricture of the ureter.

Finally, a relevant point is the liability of any method of drainage to allow over-distension of the bladder which, in the presence of reflux, might promote severe pyelonephritis.

The various types of initial bladder treatment may now be considered in turn:

(i) Intermittent Catheterisation. It must be said straight away that the bad results of intermittent catheterisation reported after the First World War were really the results of bad intermittent catheterisation. In theory, the intermittent withdrawal of urine from the bladder in an atraumatic and aseptic fashion is an ideal method which allows easy observation of the return of reflex function and perhaps even stimulates it. Guttmann (1949) and Guttmann and Frankel (I966) have shown that if the instrumentation is carried out by a doctor the system is safe and great credit is due to the Stoke Mandeville team for having succeeded 
in rehabilitating this discredited method in the face of much prejudice. Between I954 and I964, 476 paraplegics and tetraplegics had been admitted to Stoke Mandeville within I4 days and $62 \cdot 2$ per cent. of these had shown sterile urine on discharge. Among the 298 males followed up there had been only a 7 per cent. drop in sterility to 52.7 per cent. The total incidence of hydronephrosis was $7 \cdot 4$ per cent. and of renal calculi $\mathrm{I} \cdot 7$ per cent., with only one late death from uraemia. These results are outstanding by any criteria.

When, in spite of every care, infection of the bladder does occur, the usual emptying two or three times a day will not prevent rapid multiplication of bacteria which can double their numbers in urine every 20 minutes (O'Grady and Cattell, 1966). Unless anti-bacterial therapy is immediately effective, resort to continuous drainage will clearly be necessary. Otherwise, accidental over-distention of the bladder may result in acute ascending infection due to reflux.

(ii) Continuous Urethral Catheterisation. Here again there is a risk of equating the inherent defects of the method with the results of its faulty application. The urethritis which gave rise to abscesses, fistula, diverticula and strictures was due to crude equipment and lack of attention to detail in its use. With plastic catheters no larger than about Io $\mathrm{Ch}$. urethral infection is minimal (Gibbon 1958, 1963) and with closed drainage the urine remains sterile for a week or more. Even when bacteria can be cultured from the urine, cystitis is usually very mild and this is probably due partly to the complete emptying of the bladder ensured by the syphon effect of the small-bore drainage system. With large connecting tubes, the syphon is broken repeatedly and a sump of infected urine remains in the bladder (Cook, I960; Kyle, I968).

If a balloon catheter is used, there is a risk of stone-formation on the egg-shelllike fragments which may flake off the balloon on deflation. Such stones will harbour bacteria and may cause haematuria. Balloon catheters should be changed more frequently, and a washout should be given through a wide-bore catheter before replacement.

It should be emphasised that, in the absence of gross infection, the empty bladder does not become contracted. The wash-outs which should be given once or twice a week when the catheter is changed serve to stumulate reflex contractions and permit their recognition.

The main hazard of continuous catheterisation is blockage of the system by mucus or phosphatic debris which, in the presence of bladder infection may lead to acute pyelonephritis. The patient usually has no warning of the vesical overdistention but we have noticed stiffening of our plastic drainage tubes to be an early sign of obstruction. This change of consistency is due to a fall in temperature of about $5^{\circ} \mathrm{C}$., which is sufficient to actuate a thermocouple with a warning device. We are now experimenting with an automatic system which can monitor up to 24 catheters at the same time, and in this way we hope to be able to prevent the dreaded 'flare-up' completely.

(iii) Suprapubic Cystostomy. The old red rubber self-retaining catheter of large gauge often led to severe chronic cystitis and sometimes to a contracted bladder. A change of catheter was a difficult and traumatic process and it was therefore postponed on occasion until gross phosphatic encrustation had taken place. It is doubtful whether the avoidance of urethritis offset these serious 
disadvantages. On the other hand, a balloon catheter can be used suprapubically with relative safety and the modified Riches tube has been advocated recently for routine use in paraplegia by Kyle (1968). As the track is rigid, it is sufficient to inflate the balloon with only one or two $\mathrm{ml}$. of water and this greatly reduces the area of encrustation. Moreover, a larger catheter may be used than would be permissible in the urethra, and this will render blockage less likely, though the importance of maintaining a continuous syphon should be borne in mind.

(iv) Vesicostomy. By this operation (Lapides et al., I960), a permanent epithelial track is made between the bladder and the anterior abdominal wall, and the urine is collected in an adhesive appliance. In this way, free bladder drainage should be assured at all times and ascending infection avoided. Unfortunately, a watertight fit is difficult to maintain in the suprapubic region especially in the sitting posture and in the presence of obesity, while hair growth in the track has sometimes led to stone formation. The operation is technically difficult and has not yet earned a place in the management of even selected cases of paraplegia. So far, we have not performed vesicostomy in any of our patients.

To summarise this section it may be said that significant urethritis may be avoided by the careful use of all three methods of catheterisation described. With the exception of those cases in which bladder emptying is re-established with a sterile urine during intermittent catheterisation, cystitis is still a common complication and may lead to ascending infection, especially if over-distention occurs.

The relative safety of these methods as regards upper urinary tract complications could only be assessed by following parallel series of cases for several months or years with regular checks of renal function. To our knowledge this has not yet been done, though Wilmot and O'Flynn (I967) have given a short-term report on the relative merits of continuous and intermittent catheterisation. Urethritis and cystitis were commoner with an indwelling catheter, but it should be noted that an $\mathrm{I} 8 \mathrm{Ch}$. latex balloon catheter was routinely used. All patients on continuous drainage developed infected urine, and two-thirds of those on intermittent catheterisation. Seven patients retained a sterile urine from admission to discharge on intermittent drainage, but the periods of catheterisation were very short (two to seven days), and only one of these patients had a complete cord lesion. However, the patients who ultimately became infected on intermittent catheterisation did so only after an average of 45 days ( 2 to 74 days), and the potentialities of this method are clearly impressive.

Guttmann and Frankel (1966) have recorded the state of the urine on admission in their 409 male cases admitted within I4 days. Only seven out of I64 cases which had been treated by intermittent catheterisation were infected on arrival, compared with nine out of 44 managed with a Gibbon catheter and 6I out of IO6 with a Foley. Assuming that the duration of treatment was similar in the different groups, the results at this early stage indicate clearly the superiority of intermittent emptying and the great advantage of the small-gauge plastic catheter for indwelling purposes.

\section{FOLLOW-UP REPORT FROM THE LIVERPOOL REGIONAL PARAPLEGIC CENTRE}

This centre was opened in 1947 to house all the paraplegics scattered around the region, many of whom were war victims in desperate straits with pressure sores 
and severe urinary infection sometimes associated with the presence of large suprapubic drainage tubes. During the next few years, new patients were usually admitted with large urethral catheters after a delay of several months. Our first follow-up report on II6 cases (Damanski and Gibbon, I956) showed that over one-third of them had developed hydronephrosis and that almost one-fifth had died or were dying of uraemia.

Suprapubic Cystostomy. We have never used suprapubic cystostomy as a primary procedure, but 47 of these II 6 cases were admitted with a suprapubic tube. At the time of closure (at 2 months to eleven years-average, I9 monthsin the 4I cases in which the dates were on record) pyelography had been normal in 39 cases, but had shown bilateral hydronephrosis in three and unilateral hydronephrosis in five. In three patients, renal function deteriorated rapidly after closure of the fistula and we drew attention to the danger of this complication.

An up-to-date follow-up of these original cases and of nine others subsequently admitted with suprapubic drainage has shown a very high rate of complications. Of the 56 cases, the cystostomy had been done as a primary procedure in 42 , and secondarily in 14 (in half of these because of lower urinary tract complications). Among the primary cases, the average delay in admission to our Centre was $2 \frac{1}{2}$ years and all but two of them had pressure sores. Twenty-four of these 42 patients have died, 20 of them from renal failure, after 3-2I years (average, Io years). The I 8 survivors had lived I-24 years when last followed up (average Io years). Twelve had normal pyelograms, five had bilateral hydronephrosis, and in one the concentration was poor.

Most of these cases were dealt with during or just after the Second World War, and many of them had undergone laminectomy or nursing on a plaster bed. The disappointing results are therefore due to inexperienced general management, and cannot be attributed entirely to the method of bladder drainage.

Continuous Catheterisation. By 1957, cases were being admitted earlier and we began to treat some fresh admissions with the fine plastic catheters referred to above, usually $8 \mathrm{Ch}$. in size. These have continued in routine use in association with a closed drainage system, though in the last few years we have treated selected cases by intermittent catheterisation, with encouraging results. For comparison with series from other centres, we have analysed the fate of the traumatic paraplegics and tetraplegics admitted within I4 days of injury during the nine-year period I 958 to I966 inclusive.

During this time, a total of 4I4 new cases were admitted, I36 of them within I 4 days (33 per cent.). There were I 8 deaths in this smaller group within three months (13.2 per cent.) and in 17 other cases we lost touch with the patient on account of early transfer to another hospital or refusal to return for examination. One patient did not have retention at any time. The remaining Ioo cases have been followed up repeatedly, usually at intervals of not longer than a year (Table I).

All of these patients have been treated by continuous catheterisation as detailed above and without the routine use of anti-bacterials or penile dressings. In all, the urine became infected sooner or later, the longest sterile period being four weeks. Our policy has been to eliminate the catheter as soon as possible, and to this end bladder-neck resection and other supplementary operations have been carried out in 38 per cent. of all our cases, often within a few months of the injury 
(Gibbon, I966), though not before the patient has reached the stage of sitting or standing on account of the way in which the vertical posture may improve bladder emptying.

Late Mortality. The Ioo patients under consideration have been followed up for an average of $3 \frac{3}{4}$ years (4 months to $9 \frac{3}{4}$ years). Six late deaths have occurred, only one of these having been due to urological causes. This patient died at seven months from pyelonephritis. He had been discharged three months previously with a residual urine of only one ounce, but still infected.

$$
\begin{gathered}
\text { TABLE I } \\
\text { I958-I966 (9 years) }
\end{gathered}
$$

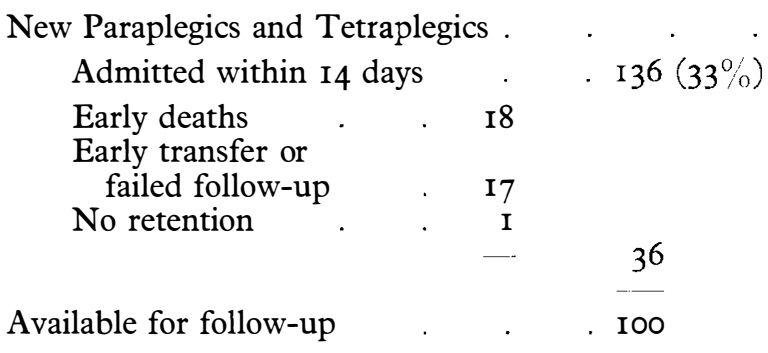

Renal Calculi. The incidence of renal stone formation serves as an indicator of stasis and infection of the upper urinary tracts in paraplegia, albeit a very coarse one. As it had fallen to almost negligible levels in our unit before the period which we are considering (Damanski, I963b) the subject will not be developed further here.

Pyelography. Of the 93 surviving patients, all but three have had intravenous pyelography at the last checkup. The appearances of the renal calyces and pelves have been strictly normal in 8I (90 per cent.). Bilateral hydronephrosis was found in five (slight in three of these) and unilateral dilatation in four (slight in two). It should be added that in several other cases earlier hydronephrosis had been eliminated by timely surgical intervention at the bladder outlet.

Infection. Up to date, we have had the services of only a branch laboratory, and our urine investigations have been limited to microscopic examination of the centrifuged deposit for pus cells and culture of the specimen, often after an undesirable delay. In the absence of anti-bacterial therapy, misleading results from culture are likely to take the form of false positives, but the white cell count will diminish progressively with delay in examination. We have therefore analysed our results with caution and drawn our conclusions with some reserve. Among the 93 survivors, six had a catheter when last checked up, one because of traumatic amputation of the penis; 28 of the remaining 87 patients had sterile urine $(32$ per cent.). In 22 of these cases, there were fewer than five pus cells per high power field, and in the other six there were from five to ten pus cells.

In 16 more cases with a positive culture, there were fewer than five pus cells, suggesting contamination of the specimen. This is supported by the finding of sterile urine in many of these patients at previous check-ups. If we add these I6 cases to the 28 with sterile urine, our infection-free rate works out at 44 out of 87 (50 per cent.) (Table II).

Residual Urine. We have always regarded as acceptable any residual urine 
which is compatible with sterility and normal pyelograms and we have paid little attention to arbitrary volumes or percentages. Of the 87 survivors without a catheter when last seen, the residual urine was under the critical volume of $30 \mathrm{ml}$. (see above) in 38 ( 43.7 per cent.). We were surprised to find that the urine was sterile in only I 4 of these cases. Six more had a positive culture with fewer than five pus cells, giving an infection rate no less than that for all the patients taken

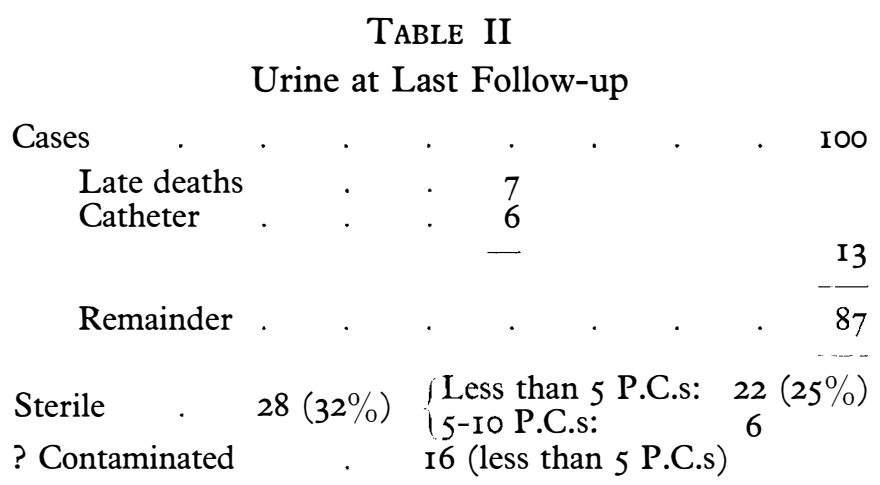

together. Diverticulosis of the bladder and dilatation of the ureters seem to account for only a small proportion of the persistent infections and there remains the disturbing possibility that some of these cases already have chronic pyelonephritis. Alternatively, some of them may not be emptying the bladder often enough or maintaining a high enough fluid intake. Further investigation seems desirable, and as serum antibody estimations are reported to offer an indication of renal involvement (Percival et al., 1964) we plan to make use of this method in the future.

\section{CONCLUSIONS}

Continuous small-gauge urethral catheterisation has virtually eliminated lower urinary tract complications among our cases. However, the persistence of infected urine in at least half of the patients at follow-up leaves no room for complacency, especially in view of the circumstantial evidence that some of them may have chronic pyelonephritis. We anticipate some improvement in our results from the use of antiseptic penile dressings, prophylactic antibacterial therapy and the introduction of an automatic alarm system for the detection of catheter blockage.

The indwelling catheter has been particularly suited to the conditions prevailing on our Centre, which, until the last year or so, has had the services of only one full-time doctor (a consultant) supported by visiting specialists. We appreciate the great value of intermittent catheterisation not only before transfer to a special centre but also in such a centre when a rota of doctors is available.

\section{REFERENCES}

BAND, D. (1963). Spinal Injuries. Edinburgh: Morrison \& Gibb, Ltd.

Cook, J. B. (1960). Proc. Roy. Soc. Med., p. 263.

Cox, C. E. \& Hinman, F. (I96I). F. Urol. 86, 739.

DAMANSKi, M. \& GibBon, N. (I956). Brit. F. Urol. $28,24$.

DAMANSKI, M. (1963a). Spinal Injuries. Edinburgh: Morrison \& Gibb, Ltd.

DAMANSKI, M. (I963b). Paraplegia, I, I49. 
DAMANSKI, M. (1965). F. Urol. 93, 466.

Doggart, J. R., Guttmann, L. \& Silver, J. R. (I966). Paraplegia, 3, 229.

GibBon, N. (1958). Brit. F. Urol. 30, I.

GibBon, N. (1963). Lancet, 2, I3I3.

Gibbon, N. (1966). Acta Neurol. Scandinav. 42, 133.

Guttmann, L. (I949). Brit. Surg. Pract. 6, 445.

Guttmann, L. \& Frankel, H. (I966). Paraplegia, 4, 63.

Kyle, E. W. (1968). Paraplegia, 6, I.

Lapides, J., Ajemian, E. P. \& Lichtwardt, J. R. (i960). F. Urol. 84, 809.

Nyquist, R. H. \& Bors, E. (1967). Paraplegia, 5, 22.

O'GRAdY, F. \& CatTell, W. R. (I966). Brit. F. Urol. 38, I49, I 56.

Percival, A., Brumfitt, W. \& DE Louvois, J. (1964). Lancet, ii, I027.

Price, M. (I968). Paraplegia, 6, 22.

Ross, J. C., Damanski M. \& Gibbon, N. (1960). Brit. F. Surg. 47, 636.

TALBOT, H. S. (1958). F.A.M.A. 168, I 595.

Tribe, C. R. (1963). Paraplegia, I, I9.

Vellacott, P. N. \& WebB-Johnson, A. E. (I9I9). Lancet, I, 733.

Wells, C. A. (1952). Prostatectomy. Edinburgh and London: E. \& S. Livingstone.

Wilmot, C. B. \& O’FlynN, J. D. (1967). Urol. Dig. 6, I7.

\title{
THE UPPER URINARY TRACT IN NEUROGENIC DISTURBANCES OF MICTURITION WITH SPECIAL REFERENCES TO NON-TRAUMATIC AETIOLOGY
}

\author{
By M. L. Allert, M.D., M. Bressel, M.D., and J. Sokeland, M.D. \\ University Hospital of Neurology, Homburg/Saar and University Hospital \\ of Urology, Homburg/Saar (Germany)
}

THE neurogenic disturbances of micturition of traumatic or non-traumatic aetiology are different in substantial aspects. Whereas the onset of traumatic lesions is immediate it is nearly impossible to determine the beginning and course of those with non-traumatic aetiology. As a result an exact classification of the type of bladder disturbance is rarely possible in the latter-in contrast to the traumatically conditioned disturbances which are usually classified according to Bors (1967). This leads to considerable problems as regards therapyand prognosis.

What is known about the upper urinary tract in such cases? Literature does not show details regarding this question-neither the classical works by Meyer (1928) and Adler (I920) nor by one of the latest authors; they primarily deal with the problem of reflux, as may be seen from the recent extensive studies by Guttmann and Frankel (1966), Walsh (I968), and Talbot et al. (1968).

We have chosen 50 patients at random with neurogenic disturbances of micturition in order to find an answer to our question. The findings were collected and analysed by means of an electronic computer-system. The corresponding method was outlined in detail at the Urologists Congress, Lüttich, in 1967 (Albert, Bressel and Sökeland). Six patients were excluded because their examination results did not allow a comparison.

Table I shows sex and age of our patients. The relation between the number of men to that of women is approximately $3: \mathrm{I}$. The youngest patient was $\mathrm{I} 6$ and the oldest 76 years old. Most were between 20 and 59 years old, the majority between 50 and 59 . 